\title{
EN EL PARAÍSO DEL INFIERNO: EL FAUSTO ARGENTINO
}

La literatura argentina anterior al establecimiento definitivo del Estado en 1880 (es decir, anterior a la autonomización de lo político y su constitución como esfera separada del espacio cultural y literario) podría leerse según la construcción de representaciones, y por lo tanto según las posiciones de los sujetos, en esta secuencia: 1) los otros: indios-negros-gauchos-inmigrantes y sus relaciones entre sí; 2) los que mandan y saben (militares-políticosestancieros-sacerdotes-doctores[abogados]), sus relaciones entre sí y con los otros; y 3) los espacios: el desierto, el campo, el interior, la ciudad, el exilio, Europa, sus relaciones y a la vez los diversos tipos de vínculos con los otros y con los que se disputan el poder. Trazado de la representación: el dibujo del mapa construye, cada vez, el Estado.

Pero si se quiere dar un paso más (si se quiere dar volumen a un conjunto de redes, que pueden hacer excesivamente planos los caminos entre subordinados, poderosos y el despliegue de los espacios), el punto de partida sería la identificación, y el juego de distancias mínimas, entre lo que se postula como político y lo que se postula como literario. Lo político es lo ya dicho: la función estatal de lo escrito en tanto instancia de unificación, con integración de unos y exclusión de otros y, además, la posición referencial o derivada de lo escrito en la coyuntura política, que es siempre un momento de las relaciones entre los sectores que se disputan la hegemonía. Lo literario es la articulación específica y cambiante cada vez entre lengua (entendida como registro y cultura) y ley (que no contiene solamente la idea de justicia, sino la de una norma general y abstracta, "racional y universal"). Esa articulación lengua-ley toma la forma de una relación entre diversas irracionalidades-particularismos (pasión, enigma, desorden, vio- 
lencia) y los valores universales postulados (libertad, progreso, justicia, unidad, civilización). A partir de esta relación, de las formas y modos múltiples que puede tomar, se definen géneros, narraciones y textualidades diversas, y se delimita otra vez el lugar de los escritores: su trabajo consiste en producir todo un encaje con diferentes tipos de conjunciones, filiaciones, exclusiones, en el interior de los vínculos entre especificidades y elementos de cohesión. El escritor, según los circuitos de interlocución en los que se sitúe, según los géneros que use y según las coyunturas políticas, distribuye las fuerzas en la lengua y en el mapa del Estado: con el mismo gesto, indiferencia política y literatura. Antes del 80 , conflicto cultural y conflicto político se identifican: los dos son uno y ése es uno de los núcleos de nuestra cultura.

Para periodizar el género gauchesco según su historia interna (y no según las etapas políticas a las que refiere linealmente) puede postularse un solo corte, el de la parodia de Fausto; es el primer texto del género que separa nítidamente literatura y política. Define la primera por exclusión de la última e introduce una secuencia típicamente moderna que puede enunciarse así: despolitización, autonomización de lo literario, problematización de las construcciones representativas del género y apertura de un debate nuevo entre los escritores, es decir, reformulación de sus funciones específicas.

Todo puede sintetizarse en un corte y un cambio de lugar; el corte es el salto producido por la progresiva despolitización de una de las líneas del género, los relatos sobre la visita del gaucho a la ciudad en ocasión de una celebración política. El cambio de lugar es, en realidad, una metáfora y un desplazamiento de la sección del periódico que enmarca lo escrito: la crónica ya no es "cívica" y política sino puramente cultural, la de una representación en el teatro Colón. Fausto despolitiza la relación entre lengua y ley (registros y código) porque se distancia de las representaciones del género y porque las leyes y convenciones "universales" son precisamente las de la representación.

Los diálogos y relatos de visita del gaucho a la ciudad pueden leerse como la contraparte exacta de los cielitos y mediacañas de celebración de la victoria militar en el campo: allí el escritor "iba" al campo (de batalla y también al lugar de la estancia) a usar el registro y la cultura oral de los gauchos para politizarlasmilitarizarlas y unir y celebrar. En la visita a la ciudad el gaucho va a los festejos políticos, ahora civiles, y contempla y usa (con dificultades y a veces con miedo) la cultura de la ciudad. La visita aparece entonces como el complemento necesario al equilibrio 
paternalista de la alianza y, a la vez, se constituye de entrada por su carácter secundario, derivado $\mathrm{y}$, como tal, problemático ${ }^{1}$.

Esta línea del género es, en realidad, un tratado sobre las relaciones civiles (políticas, comerciales, jurídicas, culturales) entre la ciudad y el campo; construye y mide esas relaciones y, por lo tanto, las alianzas que trascienden la guerra y el trabajo en el campo, los dos espacios de subordinación del gaucho (soldado, peón) que fundan el género: sus dos pactos básicos. La historia de los diálogos de visita a la ciudad es la historia de la representación, y por lo tanto de la postulación, de relaciones no necesarias ni fundamentales del género: relaciones estrictamente coyunturales. La cadena de los diálogos cuenta esa historia, que es también una de las historias, la más literaria, del género.

La visita pone al desnudo y dice directamente que no hay género gauchesco sin algún tipo de alianza o contrato. En la lógica política del género todo vínculo entre personajes, discursos, enunciados, espacios y acciones, pasa por las categorías estratégicas "aliado" o "enemigo" y toma, respectivamente, la forma del pacto y alianza, o la del enfrentamiento y guerra. Pero en la visita a la ciudad aparece un tipo de contrato a mitad de camino, donde el otro del que habla se encuentra entre el aliado y el enemigo: es la transacción comercial, los lugares donde aparece el dinero y, por lo tanto, la posibilidad de estafa ("cuento"). En la ciudad, además, existe el peligro de ser engañado por algo semejante y paralelo al dinero, de su misma sustancia: la letra escrita ${ }^{2}$. Si la

${ }^{1}$ Cf. Amaro Villanueva, Crítica y pico, Plus Ultra, Buenos Aires, 1972, p. 167. Dice Villanueva: "llegar a la Relación es apreciar cómo descaece aquel impulso civil, aquel espíritu de militancia que es el sello inconfundible de sus creaciones anteriores. El lector ve deslucirse allí, desorientada, aquella despierta sonrisa revolucionaria de otros días, no por gaucha menos sutil que la que Heine distinguiera en Byron. Esa sonrisa se va tornando gradualmente, allí, contra el mismo protagonista del relato, que es el gaucho de la Guardia del Monte, el compositor aparente de sus más notables cielitos, al ritmo de los sucesos en que transcurre su andanza festiva por la ciudad. Y esto constituye una extraña e imprevista conversión de espíritu de la musa popular de Hidalgo, por no decir una traición a sí misma". Si el mecanismo que funda la parodia es la inversión (de espacios, de procedimientos), la visita a la ciudad, en la medida en que invierte la ida al campo del escritor, ya puede leerse como parodia. No habría que inventar una historia, un desarrollo o el desgaste de formas; sólo lo secundario en la forma de la inversión y su conciencia.

2 En LUIS PÉREZ hay un texto no dialogado: "Carta de Lucho Olivares al Editor", en El Torito de los muchachos, est. prelim. de Olga Fernández Latour de Botas, Instituto Bibliográfico Antonio Zinny, Buenos Aires, 1978. Aparece en los núms. 7 (p. 26), 9 (p. 35), 11 (p. 43) y 16 (p. 57). Narra la visita de Lucho a la ciudad y sus inconvenientes con el pulpero, por la confusión entre 
serie de diálogos de visita del gaucho a la ciudad se lee como un relato único puede verse aparecer, nítidamente, la historia del género como una historia de despolitización que logra transformar el pacto en cuento. El circuito va desde Hidalgo hasta Del Campo: del pacto político de unidad ciudad-campo, el deber de ir a festejar a la patria en su aniversario, al pacto de compraventa de alma entre Fausto y el diablo.

Esa historia, condición de la ficción moderna y autónoma de Fausto, se asienta en dos series de acontecimientos narrativos específicos: los contratiempos, inconvenientes y choques que acompañan a los gauchos en sus tratos y pactos comerciales y también en sus aventuras en la ciudad. La serie de esos dos órdenes de inconvenientes traza otro mapa, que culmina en Fausto y que aparece como la crítica más radical de las representaciones de las alianzas del género.

La "Relación de las fiestas mayas" (1822) de Bartolomé Hidalgo abre la serie. Allí se inserta un pacto en el interior de otro y el cuento, la "relación", es literal. El que fue a la ciudad, Contreras, narra lo que vio en ocio y festejo, el espectáculo de la cultura de la ciudad a propósito del aniversario político. Cuenta a Chano, que no pudo ir por la herida que le produjo el encuentro a cuchillo con un domador que no cumplió el pacto comercial ${ }^{3}$. El accidente, primer choque de la serie, sirve de justificación y excusa por no haber cumplido con una obligación política: ir a celebrar el pacto nacional, la unión de la ciudad y el campo contra los ene-

papeles (dinero y periódicos políticos). El texto se abre así: "El día de San Bartolo / Como es que el Diablo anda suelto / En el mismo plan del bajo / Topé un papelón envuelto". Lucho cree que se trata de dinero y se lo da al pulpero para pagar la bebida, pero él le dice que son gacetas y lo obliga a dejar el poncho como prenda, después de una lucha. Ya afuera, pide a un "escuelero" de la Recoleta que se los lea, creyendo que se trata de $E l$ Torito, pero son diarios unitarios opositores de Córdoba. El "papelón" envuelto de la ciudad articula, identifica y confunde letra, economía, política e inconvenientes.

3 Bartolomé Hidalgo, "Relación que hace el gaucho Ramón Contreras a Jacinto Chano de todo lo que vio en las Fiestas Mayas de Buenos Aires, en el año 1822"', en E. Tiscornia (ed.), Poetas gauchescos, $3^{a}$ ed, Losada, Buenos Aires, 1974. Dice Chano, vv. 15-54: "Se me apareció, el veinticuatro / Sayavedra, el domador, / a comprarme unos caballos; / le pedí a dieciocho riales, / le pareció de su agrado / y ya no se habló palabra; / y ya el ajuste cerramos / por señas, que el trato se hizo / con caña y con mate amargo". Sayavedra, "con el aguardientazo", quiere deshacer el trato y se traban en lucha: "Se jué y me quedé caliente, / sintiendo no tanto el tajo / como el haberme impedío / ver las junciones de Mayo: / de ese día, por el cual / me arrimaron un balazo / y peliaré hasta que quede, / en el suelo, hecho miñangos. / Si usted estuvo, Contreras, / cuéntemé lo que ha pasado". 
migos de la revolución. En un momento de crisis, con peligro de traición a la revolución, Hidalgo trata de recrear el fervor patriótico que acompañó a las primeras celebraciones ${ }^{4}$. Chano quedó herido y no pudo cumplir el pacto político porque el domador Sayavedra ${ }^{5}$ no cumplió el pacto comercial; el alcohol lo ha transformado en otro, y todo otro implica lucha y peligro de ruptura del pacto. El incidente ocurre en el campo, entre iguales, es privado y se subordina al pacto político como lo que impide su cumplimiento.

A partir de este complejo se reconstituye la cadena en movimiento y el juego de la sintaxis del género. La historia libera la escena de su dependencia del pacto político y la traslada a la ciudad: la excusa por no ir se torna en motivo para ir (es en la ciudad donde se realizan las transacciones). La venta aparece, así, por presión de la poética del género que no concibe motivo que no reproduzca el vínculo constitutivo de las dos culturas, como otra de las caras de la relación entre ciudad y campo. El otro toma la máscara del "vivo" que intenta embaucar: el rico o el gringo sólo acceden al pago bajo amenaza de cuchillo. Toda transacción queda marcada por el contratiempo y prevalece entonces el peso peligroso de la ciudad: es el lugar mismo del cuento.

Se trata de un doble contexto y de una doble referencia, característica de los fenómenos del género: por un lado, en Hidalgo, una escena sintética constituida en topos (trato comercial-ruptura) que funciona subordinada al pacto político, y por el otro su autonomización y variación, que dependen de los contextos contemporáneos (coyunturas) de los escritores del género y de sus modos de construir las representaciones-relaciones. Lo que cuenta la serie, otra vez, es el proceso de despolitización de la representación del gaucho en el género; a medida que los pactos y tratos pierden su carácter público, lo comercial gana en importancia y autonomía. O mejor: lo comercial ocupa el espacio público que lo político deja vacante. Los momentos de esta cadena están marcados por los

${ }^{4}$ Cf. TUlio HalPerín DONGHI, Revolución y guerra, Siglo XXI, Buenos Aires, 1972, pp. 182 y 183: "los festejos del 25 de mayo, de desarrollo primero paralelo a las festividades devotas tradicionales, terminan por rivalizar con éxito con éstas" (se refiere a 1811 y 1812). Halperín Donghi señala que las fiestas medían "el temple político de la ciudad frente a sus gobernantes a través del entusiasmo que sus multitudes ponen en la celebración". En esos festejos "la ciudad se festeja a sí misma; ebria de su propia gloria, la «inmortal» Buenos Aires se presenta como libertadora de un mundo".

${ }^{5}$ Los caminos de otra lectura posible se abren en este nombre: Sayavedra es el que impediría a Chano cumplir con el pacto de unidad nacional. 
textos de Luis Pérez, Manuel de Araucho y Estanislao del Campo $^{6}$ : en Fausto se asiste a una despolitización generalizada que deja solas, como esferas autónomas de relación entre la ciudad y el campo, a la comercial y la cultural, encarnadas en los dos protagonistas del diálogo: Laguna y su venta de lana con inconvenientes, y Pollo y su visita accidentada al teatro donde asiste a la representación de otro pacto, la venta del alma.

Y a medida que cambia la función del gaucho, cambia la del escritor: esa correlación es la base del género.

La alianza constitutiva del género postula un nosotros múltiple: por un lado alude a los dos sectores, de la ciudad y del campo, que enfrentan juntos al enemigo político y militar: es el nosotros estricto de la alianza política. Pero ese nosotros refiere a la vez, en tanto el registro verbal es únicamente el del campo, a "los que hablamos de este modo", frente a un "ellos" de la ciudad o letrados (y además, y por otra parte, a "los que cantamos y escribimos": los poetas de las dos culturas que unen las modulaciones de sus registros). Y la alianza verbal y cultural, que sólo el género realiza, se constituye en la unión del cuerpo de una enunciación, entonación y registro orales y. populares, con un enunciado y un

${ }^{6}$ LUIS PÉREZ, en el diálogo que nos ha llegado inconcluso, "Diálogo que tuvo lugar entre el Sr. Chuche Gestos y Antuco Gramajo, con motivo de las fiestas en celebridad del ascenso al mando del ilustre Restaurador de las leyes Brigadier General D. Juan Manuel de Rosas, dedicado por su autor a S.E." (1835), en JORGE B. RIVERA, La primitiva literatura gauchesca, Jorge Álvarez, Buenos Aires, 1968, p. 173. Chuche dice que no pudo ir a la ciudad porque rodó del caballo y se encuentra "con las espaldas inchadas" (el accidente es literal, desligado del trato económico). El otro cuenta cómo se festejó la prolongación del mando de Rosas con la suma del poder público. En Pérez la visita política conserva y reitera la tradición de Hidalgo. MANUEL DE ARAUCHO: en "Diálogo de dos gauchos, Trejo y Lucero" (1835), en JORGE RIVERA, op. cit., p. 163, dice Lucero: " $¿ D e$ aonde he de venir? del pueblo / que casi me han traginao; / amigo el diablo anda suelto. / Fui a ver a un viejo ricacho / que me debía cien grullos, / de un aparte de ganao, / porque él tiene matadero...". El hombre no quiere pagarle porque "la plata ha bajao"; "Ni un medio tengo" (me dice) / "porque me encuentro quebrao"... / Eché mano al alfajor / diciéndole: ladronazo, / largue el mono, hijo de angúlo / o si no le saco el guáno. ESTANISLAO DEL CAMPO: en Fausto (Poetas gauchescos, ed. cit.), dice Laguna: "-Hace como una semana / que he bajao a la ciudá, / pues tengo necesidá / de ver si cobro una lana; / pero me andan con mañana, / y no hay plata, y venga luego: / hoy no más cuasi le pego / en las aspas, con la argolla, / a un gringo, que aunque es de embrolla, / ya le he maliciao el juego" (vv. 111-120). Obsérvese, además, la transformación del otro, el que intenta romper el pacto: del domador Sayavedra, pasando por el "viejo ricacho", hasta llegar al "gringo". 
cuerpo de ideas políticas y jurídicas escritas y letradas. Cuando el gaucho va a la ciudad se encuentra precisamente con los que hablan de otro modo o, mejor, con el enunciado y la letra, la otra cultura. En Hidalgo, Contreras cuenta a Chano cómo los fuegos le cribaron el poncho, que montó en el rompecabezas y lo "tiró al infierno"' , que perdió su dinero en el juego, que no pudo ver las comedias porque una vez estaba cansado y porque otra vez ardió un vaso y huyó por temor al incendio. Pero estos inconvenientes, siempre subordinados y alternando con el festejo político, ligados con la tradición del rústico en la ciudad, con la posible producción de risa en el auditorio (lector), con el hecho de que el gaucho solo siempre narra carencias y dificultades, se transforman otra vez, en la medida de la despolitización, y acentúan la diferencia cultural. Los "fuegos" que molestan a Contreras proliferan, las dificultades se multiplican, y en Ascasubi aparece la encarnación de los puebleros astutos, los doctores. Fuegos y doctores se ligan con el infierno, el diablo y la posibilidad de ser engañados en pactos y pleitos; la conclusión es la identificación ciudaddoctores-cuento-diablo, es decir: ciudad, infierno, letra, ley ${ }^{8}$. Para el

7 Véase BARTOlOMÉ Hidalgo, op. cit., vv. 14, 38, 161, 193 y 215, donde se reiteran los núcleos "infierno" y "diablo".

${ }^{8}$ En el primer diálogo de ASCASUBI en Uruguay, "Jacinto Amores, gaucho oriental, haciéndole a su paisano Simón Peñalva, en la costa de Queguay, una completa relación de las fiestas cívicas, que para celebrar el aniversario de la jura de la Constitución oriental, se hicieron en Montevideo en el mes de julio de 1833" (en Paulino Lucero, Eds. Estrada, Buenos Aires, 1945, pp. 27,31 y 39); dice Simón: "Pero, amigo, ¿quién lo mete / en juegos de la ciudá? / ¿No sabe que los puebleros / son capaces de embrollar / al gaucho más orgulloso?' En este diálogo proliferan los inconvenientes (perdió en el juego, peleó con el pulpero, rodó con el caballo, recibió el insulto de las mujeres) y, como en la "Relación" de HIDALGO, se traza un mapa social de la ciudad, es decir, de los que comparten el poder. Compárese la descripción de Hidalgo con la de Ascasubi. En Hidalgo: "Más tarde la soldadesca / a la plaza jué dentrando / y, desde el Juerte a la Iglesia, / todo ese tiro ocupando. / Salió el gobierno, a las once, / con escolta de a caballo, / con jefes y comendantes / y otros muchos convidados, / dotores, escribanistas, / las justicias a otro lao, / detrás de la oficialería / los latones culebriando; / la soldadesca hizo cancha / y todos jueron pasando / hasta llegar a la Iglesia" (vv. 130-144), En Ascasubi es la vestimenta (la apariencia) que se pone en primer plano: " $¿ Y$ la soldadesca? ¡Ah, cosa! / Encantao estaba yo / viéndola tan currutaca / luciendo en la formación, / cuando la musiquería / redepente resonó, / al tiempo que de la iglesia / el gobierno despuntó / con toda la oficialada / saliendo de la función. / ¿Qué uniformes galoniaos! / ¡qué penachos de color! / ¡qué corbos y qué murriones / relumbrantes como el sol! / Luego con los melitares / entreverada salió / una manada de escuros, / vestida de casacón / y fachas de terute- 
que escribe, el ataque a los doctores implica la correlativa exaltación de los militares o hacendados, como ocurre respectivamente en Ascasubi y Pérez; el diálogo de visita a la ciudad puede despolitizar al gaucho (a la representación de alianza con el gaucho), pero politiza siempre la voz del escritor como representante de alguno de los sectores enfrentados. Si la visita a la ciudad es, como toda narración, el cruce de una frontera, la entrada del gaucho en el otro mundo implicaría su despolitización y la politización nítida de la otra parte del pacto, la de los escritores que, entonces, se enfrentan en tanto representantes de alguno de los grupos de poder que se disputan la hegemonía o, como en Fausto, en tanto constructores de representaciones, es decir, sin representación y a propósito de ella, hablando de sí mismos.

Lo que en Hidalgo se ligaba de un modo (el pacto comercial y sus inconvenientes, los choques en la ciudad, y todo subordinado al pacto político, fundamentador del sentido), pasa por un proceso de disgregación y autonomización de esferas; el escenario de la ciudad hace posible esa separación. Entre el festejo político en la plaza y la concurrencia al Colón se sintetiza este proceso: dos lugares opuestos de la vida pública (y de los periódicos): el espacio popular por excelencia, el de la mezcla de las dos culturas, y el espacio propio, exclusivo, de la cultura del letrado y de la ciudad: el lugar donde se representa la cultura europea ${ }^{9}$.

ros; / porque traiban el calzón / no más que hasta la rodilla; / de ahí, espadín y bastón, / y zapatos con hebillas, / y un gran sombrero flauchón... / vestimenta singular / que usa todo ese montón / de alcaldes y escrebenistas, / y dotores, como son / todos por lo rigular: / gente, amigo superior / para armarle una tramoya / y chuparle el corazón / al diablo, si se le antoja / el meterse a pleitiador"'. Toda degradación de los letrados se acompaña de una correlativa exaltación de los militares. T. HALPERín DONGHI dice que en los festejos revolucionarios la gloria militar es exaltada en primer término: "La utilización política del prestigio militar presupone la existencia de un consenso de opinión que reconoce a ese prestigio como eminente por sobre los talentos administrativos y políticos"' (op. cit., p. 212, cf. también p. 222). Ascasubi no reconoce - no representa - otras relaciones de los gauchos, salvo las que pasan por la militarización. En este diálogo, Jacinto es detenido a la entrada del teatro porque usa poncho, y es un militar quien lo hace entrar: "En esto un don Chutipea / vestigo de melitar, / agradao de mis razones, / de la mano me hizo entrar, / así no más emponchao... / ¡Vaya un hombre liberal!' La alianza entre el militar y el "gaucho bueno" es el núcleo fundamental de los textos de Ascasubi: "'Entre un gaucho y un pueblero / no encuentro disigualdá / cuando el primero es honrao / y se sabe comportar"' (p. 39). La despolitización de la cultura popular, su exclusiva militarización y la división entre gauchos buenos y malos, en Ascasubi, constituyen el núcleo del populismo oligárquico.

${ }^{9}$ La visita a la ciudad se cierra en la iconografía: hay una lámina del 
En síntesis: Fausto se constituye por exclusión de lo político. Transforma definitivamente la visita político-cultural en puramente cultural y cambia así la representación del sistema de relaciones del gaucho con la ciudad, y por lo tanto el vínculo y la alianza de las dos culturas en el género. Los efectos de la despolitización son múltiples: el texto se autonomiza y transforma su relación con la coyuntura, el contexto y el conjunto del sistema de referencias. Aparece por primera vez un poema gauchesco desligado del periodismo, absolutamente "literario", que corta en dos partes el género: Fausto no sólo es un avatar necesario de su historia y consecuencia de su lógica, sino una de las condiciones fundamentadoras de Martín Fierro.

El primer efecto de la despolitización es la mutación del acontecimiento y simultáneamente de la relación entre el marco y lo narrado. El género se constituyó con la institución de un tipo específico de relación entre el marco enunciativo (la puesta en escena del hablante, su registro y la situación en que se encuentra: oralidad popular y familiar) y lo enunciado-narrado (el acontecimiento político y las ideas cultas traducidas a la oralidad gauchesca). En Fausto los gauchos amigos no se encuentran en el campo (no hay visita de uno a otro) sino que convergen en un lugar intermedio entre ciudad y campo, el bajo entre las dos culturas. El espacio desde donde se enuncia, y el del sujeto de la escritura, está puesto en ese entre, en el neutro. Y lo que se cuenta no es un acontecimiento político o militar, ni la visita a la ciudad para la fiesta cívica, sino otro tipo de "novedad" datada y coyuntural: una representación escénica en el Colón. Se mantiene el enunciador gaucho y la modalidad del enunciado: el acontecimiento ocurrió efectivamente y es "verdadero" (y el texto puede leerse como una nota periodística cultural sobre lo ocurrido, en otra parte del periódico y del espacio público), pero lo ocurrido, y ésta es la segunda transformación del estatuto del acontecimiento, no es para el narrador el mero acontecimiento de la representación, sino lo que la repre-

almanaque Alpargatas del mes de mayo de 1946 dibujada por Luis Medrano. Se titula "Semana de mayo", y tres criollos de ojos desorbitados, ricos (caras más oscuras, bigotes, botas y chalinas), caminan guiados por un chico "vivo", al hotel "La confianza". Atrás la cúpula del Congreso, y en la Avenida de Mayo otros rostros, más claros. No conozco mejor representación de la tradición gauchesca de los diálogos de visita a la ciudad: la de la representación de la posición infantil (es un chico el que los guía y embauca) y dominada del desconocimiento del código. La ironía del nombre del hotel, en primer plano, dirige la escena y anticipa los contratiempos. Es posible que la década del 40 incluva el cierre de la tradición gauchesca. 
sentación representa: un "sucedido". En esta doble transformación del acontecimiento (de político-cultural a artístico-cultural, y de una representación a lo que representa como acaecido) se levanta el texto.

La relación entre la ocurrencia del acontecimiento y su estatuto de verdad pasa por las creencias. El Pollo, narrador de la ópera como "efectivamente ocurrida", cree porque ve: ha sido testigo de la aparición del diablo en persona. Se trata de un cuento de aparecidos (un sucedido) difícil de creer pero cierto. El gaucho cree porque ve, porque cree en la existencia real del diablo, y porque carece de la categoría de representación y de la convención de lo verosímil. Arte y superstición aparecen de entrada ligados por la creencia; creencia "religiosa" y creencia "artística" despliegan sus relaciones de sustitución. Y el contrato moderno entre ver y creer (el contrato "racional" que enfrentó las creencias y les opuso el principio de que sólo es real y verdadero lo que se ve) sostiene las relaciones. Los gauchos creen en los simulacros (teatro y diablo) porque los ven: las dos culturas se abrazan, ahora, en sus cuentos y creencias. $Y$ de este círculo sale otro: el de la creencia en lo que se dice, puesto que Pollo narra lo que vio a Laguna. Laguna cree, aunque con algunas vacilaciones al principio ("¿sabe que se me hace cuento?"), pero Pollo acude al consenso: "lo ha visto media ciudá". Laguna cree porque también cree en los aparecidos, pero además porque Pollo, el viejo que cuenta, es una autoridad y ha apelado a la objetividad de su visión.

Superstición (religión), arte y, ahora, política, pueden explorar sus vínculos en los cuentos de Fausto. En la constitución del pacto liberal como consenso, el fundamento es saber hacer que le crean. Persuadir, convencer, hacer creer: allí aparece el sentido del género gauchesco en una de sus direcciones, hacia las masas rurales. Representar al gaucho patriota de un modo tal que persuadiera de la necesidad de integrarse al ejército contra la coacción de la leva. El género anterior a Fausto es manifiestamente productor de consenso político y militar. Pero el saber hacer creer puede usarse, también, para engañar, para hacer un cuento. Y en Fausto, que sólo habla de saber, ver, contar, las creencias pasan por la categoría artística de la representación. Fausto no solamente produce un desplazamiento del espacio público sino también un cambio de lugar del discurso verdadero en el género gauchesco.

El encuentro de los dos gauchos está narrado, a su vez, por una voz sostenida por la ironía: a là inversa de Pollo, para quien todo lo que ve es real y verdadero, este primer narrador divide "ver" y "creer" con ayuda de otra escisión de la verdad, entre 
"ser" y "parecer". Usa los topoi del género anterior (encuentro de los gauchos, saludos, referencias exaltatorias a los caballos, ofrecimiento de bebidas) como un espectáculo, y dice: "imozo jinetazo! ¡ahijuna! / como creo que no hay otro" (vv. 7-8); " ¡Ah criollo! si parecía / pegao en el animal" (vv. 11-12); "de suerte que se creería / ser no sólo arrocinao" (vv. 15-16); “Qué!... si tráia, para $m i$, / hasta de plata las bolas!" (vv. 29-30); "que sus dos almas en una, / acaso se misturaron"' (vv. 63-64, los subrayados son nuestros). Se recuesta en la subjetividad (es el parecer lo que hace creer), mientras Pollo lo hace en la objetividad y en los otros. Es un narrador irónico: menciona los enunciados del género pero invita al mismo tiempo a no creer o, mejor, a creer como se cree en una ficción o representación: suspendiendo la incredulidad. Cuenta el encuentro de los amigos, que abre los diálogos gauchescos de visita a la ciudad, como si viera o leyera un simulacro o representación con gauchos irreales. Lee desde el Colón. Si Pollo narra la representación como ocurrida en la realidad (y genera entonces una escisión en el acontecimiento, al que se aplica una mirada y un registro verbal diferentes de los que le cuadran), el primer narrador, por la modalidad irónica, separa la mirada culta del registro verbal -el ojo de la lengua - y se escinde él mismo entre lo que ve (o le parece que ve) y cree. Divide enunciación y enunciado: lo que dice la primera es contrario a lo que dice el segundo. El resultado es que el encuentro de los gauchos aparece tan ficticio y teatral como la ópera. En la ironía como antífrasis y duplicación de la palabra del otro se resume la lectura "culta" y poética del género (del mismo modo que en el relato de Pollo se resume la lectura popular de la representación): se trata de una ficción representativa (de una convención) que no puede pasar por realidad (y eso es sobre todo lo que dirá Hernández de Fausto en el Prólogo de la "Ida". Pero la ironía produce efectos de ambigüedad y paradoja, por momentos es indecidible y puede generar double-bind. Según los destinatarios hay decodificación literal o irónica (antifrástica), y esto es lo que ha ocurrido en los comentarios sobre los errores y el desconocimiento del medio rural de Del Campo $^{10}$.

${ }^{10}$ Los juicios sobre Fausto en el momento de su aparición muestran claramente que fue Hernández, en la Carta Prólogo de la "Ida", el que introdujo el debate y cambió las lecturas. Tanto José Mármol como Juan Carlos Gómez ven nítidamente que lo que ha hecho Del Campo es un mixto; dice GÓMEZ: "En esta importación de la leyenda de la edad media, en esta nacionalización del poema metafísico" ("Juicios críticos sobre Fausto de Estanislao del Campo" en A. Villanueva, op. cit.). Y Ricardo Gutiérrez lamenta que 
El texto opera entonces sobre los dos polos del género y las dos culturas: cada parte sostenida por un narrador es contada desde la modalidad, el modo de representación y la creencia que corresponde a la otra cultura. Cada parte, y cada narrador, se fundan en un tipo de texto y un tipo de convención y tradición literaria y cultural, y su rasgo común o el punto donde puede construirse la alianza es que las dos son, por así decirlo, mixtas: el género gauchesco, escritura de lo oral, hecho del abrazo de la cultura popular y la letrada, y la ópera, texto letrado en versión oral, canto fundado en lo escrito, literatura oralizada hecha sobre un texto culto construido sobre una leyenda popular oral (Del Campo habría trabajado, por otra parte, sobre el libreto escrito, del mismo modo que Hidalgo trabajó su Relación sobre la crónica periodística, aparecida en el número 39 de $E l$ Argos, el sábado $1^{\circ}$ de junio de 1822 ,

para comprender totalmente el texto sea necesario conocer el de Goethe y la "sublime partitura del genio francés". Carlos Guido y Spano habla directamente de parodia: "Su parodia está llena de gracia, de novedad y frescura", y critica la sociedad urbana, llena de galas postizas por la adopción de costumbres exóticas. Nadie cuestiona la verosimilitud, nadie habla de burla al gaucho, nadie hace una crítica política. Todo cambia a partir de Hernández, que enfrenta directamente, desde el género, la representación del gaucho en Fausto: "Quizá la empresa habría sido para mí más fácil, y de mejor éxito, si sólo me hubiera propuesto hacer reír a costa de su ignorancia, como se halla autorizado por el uso en este género de composiciones". Y más adelante: "Por lo demás espero, mi amigo, que Ud. lo juzgará con benignidad, siquiera sea porque Martín Fierro no va a la ciudad a referir a sus compañeros lo que ha visto y admirado en un $\mathbf{2 5}$ de mayo u otra función semejante, referencias algunas de las cuales, como el Fausto y varias otras, son de mucho mérito ciertamente, sino que cuenta sus trabajos, sus desgracias, los azares de su vida de gaucho, y Ud. no desconoce que el asunto es más difícil de lo que muchos se imaginarán". A partir de entonces se reitera el lugar común "Fausto, burla del gaucho", que aparece sobre todo en Lugones y en Martínez Estrada. Dice L. LUGONES: "Su conocida composición es una parodia, género de suyo pasajero y vil. Lo que se propuso fue reírse y hacer reír a costa de cierto gaucho imposible, que comenta una ópera trascendental cuyo argumento es un poema filosófico. Nada más disparatado, efectivamente, como invención. Ni el gaucho habría entendido una palabra, ni habría aguantado sin dormirse o sin salir, aquella música para él atroz; ni siquiera es concebible que se le antojara a un gaucho meterse por su cuenta a un teatro lírico" (El Payador, cap. 7, en Obras en prosa, Aguilar, Madrid, 1962). Como se ve, Lugones lee según las reglas de la verosimilitud realista, y no según las de la parodia a pesar de haberla reconocido. Dice E. MARTÍNEZ ESTRADA, Muerte y transfiguración de Martín Fierro, t. 1, F.C.E., México, 1948, p. 294: "Del Campo ridiculiza al gaucho haciéndolo dialogar e interpretar lo que ha visto en la ciudad -es el juego de Hidalgo-", y más adelante, el otro lugar común, "lo pintoresco": "Del Campo había insistido en la factura de los Diálogos de Hidalgo, acentuando 
que narra lo ocurrido en las “Fiestas cívicas de Mayo de 1822"'). El primer efecto de la despolitización consiste entonces en la transformación del acontecimiento, de los marcos y narradores, y en el llenado del relato con dos tipos de cuentos, sus modos de representación y lecturas constitutivas de las dos culturas, en un bucle que las trenza: las creencias cruzadas sostienen el texto. El "arte" aparece como equivalente de la superstición popular; el género gauchesco como una construcción de ficción y un espectáculo; el consenso es artístico.

En el debate interno a Fausto alrededor de la ley de lo verosímil del género gauchesco, los códigos artísticos y sus lecturas, la parodia quiere decir, también: estas formas son imposibles. Aquí Fausto cierra efectivamente la línea dél género de visita a la ciudad y, quizás, el conjunto de los diálogos gauchescos teatrales y operísti-

lo pintoresco en la ignorancia del gaucho pero sin el propósito del precursor"'.

En cuanto al desconocimiento del campo y sus costumbres, todos los lugares comunes (sobre el "overo rosao" y el abrazo de los gauchos, entre otros) provienen de RAfael Hernández, Pehuajó. Nomenclatura de las calles, Intendencia Municipal de Pehuajó -Secretaría de Cultura, Educación y Difusión, 1967. En la calle, Del Campo dice (después de confundir al que va a cobrar la lana con el que va al teatro, a Laguna con Pollo) que el overo rosado es "manso, galope de perro y propio para andar mujeres" (p. 48). Con respecto a los versos "Capaz de llevar un potro / A sofrenarlo en la luna", dice que a un potro no se le pone freno sino bocado, y que "sofrenar el caballo no es propio de criollo jinete, sino de gringo rabioso" (p. 49). Finalmente, los amigos que se abrazan: "¿Quién vio abrazarse dos gauchos? -Ni para bailar" (p. 49).

Para BORGES el sentido no surge de los particularismos ni de las circunstancias, sino de los valores universales: "Más importante que el pelo del impugnado overo rosao, al cual no se le permite ser parejero, y que algunas comparaciones inverosímiles, es el espléndido espectáculo de amistad que propone el Fausto. Lo valioso es la venturosa y clara amistad que el diálogo de los aparceros trasluce" (El "Martín Fierro", Columba, Buenos Aires, 1953, p. 17).

Solamente E: ANDERSON IMBERT (Análisis de "Fausto", C.E.A.L., Buenos Aires, 1968), deja de lado estas lecturas y extiende la ironía: "'los burgueses de Buenos Aires que asistieron al estreno de Fausto en el Teatro Colón se creían muy europeos pero eran tan fronterizos con respecto a París como los gauchos con respecto al Teatro Colón" (p. 29). Habla también de la "simulada seriedad de los gauchos", de la "mentira artística", y analiza las formas del texto. También dice: "Para exaltar el Martín Fierro se cometió la injusticia de rebajar el Fausto" (p. 47). Para EDUARDO ROMANO una parodia no implica intención de ridiculizar al gaucho (Sobre poesía popular argentina, C.E.A.L., Buenos Aires, 1983, p. 25), y para LEÓNIDAS LAMBORGHINI ("El gauchesco como arte bufo", Tiempo Argentino, 23 de junio de 1985) la parodia es sobre todo de la ópera, la "demolición del Modelo" europeo, el "Modelo-Autoridad". Lamborghini lee todo el género gauchesco como paródico y bufo, burla del sistema y del proyecto civilizador. Lo lee desde la resistencia. 
cos ("El gauchesco como arte bufo"). Ya habían preparado la parodia los marcos "escritos", los partes y cartas de los gauchos de Pérez y Ascasubi, y las exageraciones grotescas de Aniceto el Gallo. El diálogo de las dos culturas se realiza en Fausto entre el género gauchesco y la poesía culta; las dos se encuentran y se parodian entre sí: la lectura produce risa por el contacto y biasociación de dos modelos aparentemente incompatibles. Pero la parodia se inscribe en una concepción de la literatura como sistema autónomo y juega en el interior de esa concepción al leer un sector (género, texto, convención, registro) desde otro, opuesto y alternativo, que aparece como su complemento en el sistema. La parodia representa entonces un conflicto puramente cultural, y su estrategia pragmática lleva al lector a participar en ese conflicto: en vez de oponer dos sectores políticos, económicos, militares, se enfrentan dos espacios literarios, culto y popular. Es el mismo conflicto del gaucho en la ciudad, representado en la forma de los inconvenientes. El enfrentamiento de los dos sectores culturales toma en Fausto la forma de parodia, modo intermedio entre la guerra y la alianza, relación ambigua y doble: transformación del pacto en cuento. $\mathrm{Y}$ al parodiar el género gauchesco, al leerlo desde la poesía culta y con sus leyes, se lo constituye, en ese mismo momento y también retroactivamente, en género literario.

Dicho de otro modo: la parodia despolitiza o, mejor, descontextualiza el género en su relación con la política, porque cuestiona la referencialidad de la representación y la lleva a la literatura misma. Y las luchas, alianzas y sectores enfrentados se trasladan masivamente a la cultura, con sus dos posiciones, opuestas y a la vez mixtas. En cada sector cultural se encuentra una teoría del "original" y una teoría del "sistema": para la estética del género gauchesco anterior ( $y$ también, en parte, para la de Hernández), el discurso literario duplica, reproduce y refiere directamente a la realidad. Los textos aparecen como partes (o derivados, secundarios) que deben complementarse afuera para constituir la totalidad heterogénea "signo más realidad" que merece la categoría de verdad. La literatura es un brazo de lo otro, político y original. En la parodia, en cambio, como en todos los procesos de autonomización de la literatura y de su exhibición como institución, la totalidad o el sistema se encarna en la relación homogénea entre discursos (géneros, "estilos", convenciones): la totalidad es literaria, cultural y semiológica. Se trata de una red de textos en cadenas de filiaciones, y de alianzas-enfrentamientos entre escritores y entre nombres: Aniceto el Gallo y Anastasio el Pollo. La parodia transforma en convención todo lo que toca, corta las 
relaciones referenciales con el mundo, instala un lugar desde donde se lee y también instala lo escrito en una familia: parodia es estética del hijo.

La marca más fuerte de la autonomización es el surgimiento, en Fausto, de un discurso sobre la literatura gauchesca en el interior mismo del género. Pero ese discurso sólo puede hacerse ahora desde la otra literatura, desde el Colón. El efecto de la parodia, del cambio de "original", del cierre contextual y de la autonomización es que el género se literaturiza o estetiza (y en su tema mismo): no solamente porque corta el vínculo con la crónica política y se instala en la crónica cultural, sino porque hace ver, al mostrar las convenciones, que el género es un puro artificio y que trabaja del mismo modo que la poesía culta contemporánea.

En Fausto el género se ficcionaliza por inversión paródica de algunos topoi y por exageración paródica de otros. Se desmienten, o se muestran como cuentos, los ejes de la gauchesca anterior: los encuentros, el tema de los caballos, la guerra, la pobreza del gaucho, el tono del lamento. El encuentro de los amigos contiene el cuento de Laguna sobre la fidelidad del caballo, que Pollo no cree (identificándose con el primer narrador en su división irónica): "Ya una vez, cuando el abasto, / mi cuñado se desmayó; / a los tres días volvió / del insulto y, crea amigo, / peligra lo que le digo; / el flete ni se movió” (vv. 85-90). Y Pollo: “__Bien haiga gaucho embustero! / ¿Sabe que no me esperaba / que soltase una guayaba / de este tamaño, aparcero?' (vv. 91-94).

Laguna tiene dinero, ganó en el juego (en los textos anteriores del género los gauchos eran desvalijados) $\mathrm{y}$, sin embargo, se queja de la pobreza. Dice Pollo: "-Con el cuento de la guerra / andan matreros los cobres", y Laguna: "-Vamos a morir de pobres / los paisanos de esta tierra. / Yo cuasi he ganao la sierra / de puro desesperao..." (vv. 121-125). Pero es también un "cuento" que Pollo desmiente rápidamente: "—iVaya un lamentarse! ¡Ahijuna!... Y eso es de vicio, aparcero; / a usté lo ha hecho su ternero / la vaca de la fortuna. / Y no llore, don Laguna, / no me lo castigue Dios; / si no, comparémolos / mis tientos con su chapiao, / y así en limpio habrá quedao / el más pobre de los dos"' (vv. 131-140). La queja de Laguna como cuento está confirmada por el texto mismo: al final, saca "el rollo" y paga la comida de los dos. Los cuentos que podían hacer los "vivos" de la ciudad son en Fausto los temas y convenciones de la tradición del género que, ahora, se dirigen entre sí, sin creerlos, los gauchos amigos.

La guerra, una de las condiciones fundamentadoras del género, no sólo aparece como cuento sino que es la presente, la del Para- 
guay (Valentín, de la ópera, fue allí, dice Pollo, vv. 490-494), pero vista y vivida, en el relato de la ópera, no desde el campo de batalla y el ejército, sino desde la ciudad. Esta inversión de la perspectiva y del espacio de la guerra define claramente al texto en su relación con el género: en Fausto se contaría qué ocurre a los que no van a la guerra (mujeres y doctores), a los que quedan en la ciudad mientras militares y gauchos luchan.

$\mathrm{El}$ gaucho en Fausto recita en su registro los núcleos, temas y formas de la poesía culta contemporánea (Del Campo era, además, un poeta culto): el amor, la mujer, el paisaje, el tiempo, que aparecen, leídos desde el género, como antigauchescos ${ }^{11}$, en la medida en que no se vinculan con la guerra y los procesos políticos. La poesía culta introduce en Fausto un gesto universalizante: otro cambio de lugar, esta vez de los universales. Este gesto distancia el género de la coyuntura y del acontecimiento puntual; se trata de cualquier hombre, amor y mujer. En la constitución misma del género la palabra letrada impuso la dimensión universal en los versos neoclásicos de Hidalgo y las loas a la libertad y la igualdad. La palabra culta, general y abstracta, la palabra burguesa, se lee en la discusión sobre la integración del gaucho a la ley y, en Ascasubi, en las apelaciones a la libertad, por la que los gauchos deben luchar contra la tiranía. Esa palabra universal era la del ideólogo político. Ahora surge la dimensión universal de la otra cara del hombre: nace el sujeto, el cuerpo y el deseo. Es decir: nace el espacio privado recortado contra el espacio público y correlativo del hombre universal. La categoría de la universalidad es contemporánea de dos movimientos: en el interior de la cultura burguesa, del establecimiento de la subjetividad y la esfera íntima, que la literatura no deja de trabajar y, en la cultura popular, del surgimiento de la resistencia y del doble sentido, que cuestiona esa universalidad y la particulariza: ésa es la materia de la "Ida" de Martín Fierro. El traslado de los universales políticos al sujeto, que Fausto produce en la gauchesca, lleva directamente al canto de la "Ida": "el hombre que lo desvela / una pena estrordinaria".

11 El género incorpora, en adelante, la mujer y el amor, aunque con sentidos diferentes. En Los tres gauchos orientales de ANTONIO LUSSICH (1872), Centurión se extiende sobre esos tópicos (vv. 590-669) pero Julián lo detiene y marca que ése no es el tema del diálogo (vv. 762-765): “Deje a las hembras atrás / Que ya cansó la tal yerba, / ¡Cargue pues con la reserva / Y cuente algo de esta paz!" (Marcha, Montevideo, 1972). El amor, en la primera parte del Martín Fierro (cf. Cruz), tiene un sentido diverso: aparece, en su negativo (pérdida de la mujer) como un aspecto más de la opresión de los gauchos. 
Pollo no habla solamente del amor y del paisaje; el topos de la queja por el tiempo pasado feliz y la desgracia del actual, que en los poemas gauchescos anteriores aludía a la coyuntura política, se refiere en Fausto al tiempo biológico del sujeto. Pollo está viejo y se queja: "¿no es el Pollo?” dice Laguna, y la respuesta: "-Pollo, no; / ese tiempo se pasó, / contestó el otro paisano, / ya soy jaca vieja, hermano, / con las púas como anzuelo, / y a quien ya le niega el suelo / hasta el más remoto grano"' (vv. 53-60). En la modernización del género que Fausto introduce desde la cultura "alta", por la parodia de sus convenciones, se asiste a una verdadera promoción de lo subjetivo e individual. Esta subjetivación es uno de los procedimientos centrales de distanciamiento del contexto social y de corte con la coyuntura política ${ }^{12}$. Dicho de otro modo: universalización de lo privado y autonomización son casi sinónimos; universalizar es hacer significar la literatura más allá del espacio en que surge, y a la vez producir un sentido que distancie los intérpretes de su espacio. Por primera vez la voz del gaucho, que a través de la ópera habla de una tradición cultural que surge con el carpe diem, es oída como la voz del hombre.

A la despolitización de la representación, la autonomización, la parodia de las convenciones del género y su exhibición como ficciones, y a la universalización del sujeto, se añade un gesto fundamental de Del Campo: su donación de la recaudación por la venta de Fausto, impreso como folleto, a los hospitales militares que atendían a los heridos de la guerra del Paraguay. Allí está la coyuntura política, la guerra y los soldados gauchos, constitutivos del género. Otro desplazamiento de espacios, y esta vez un espacio fuera del texto. El gesto está afuera de Fausto, en otro espacio público, pero dentro del género y sirve para redefinirlo, en tanto sitúa lo excluido y ficcionalizado en otra zona, confirma el corte y le da otro marco (un texto no es una miniatura del género; un género ocupa el espacio interior y exterior común a muchos textos). La exclusión de los datos fundamentales y de las condiciones del género reaparece como texto y gesto otra vez con la "Ida", junto a ella, acompañándola: la voz letrada y la política modernizadora, presentes todo el tiempo en Fausto, pero ausentes en las palabras de Martín Fierro y Cruz (o incluidas para rechazarlas y negarlas), se hacen presentes en El camino trasandino. Del Campo y Hernández, en gestos idénticos e inversos, confirman la falta, en sus poemas, a las tradiciones del género: confirman

12 Cf. Predrag Matvejevitch, Pour une poétique de l'événement, Union Générale d'Éditions, Paris, 1979, p. 96. 
que cambian el género, reorganizan su espacio, y que excluyen de los textos lo que ponen en el género pero afuera, a la par.

Fausto innova en la construcción del marco de los diálogos gauchescos; los textos anteriores se abren con la voz "directa" del gaucho y se cierran con otra, la del que escribe el diálogo y que a veces lo dice; constituyen pues un marco mixto, mitad "oral", mitad "escrito", que reproduce la alianza. Ahora el marco (y los guiones que introducen las voces que reemplazan a los nombres de los personajes) pertenece totalmente al orden de la escritura; es el mismo narrador, que "contempló" el encuentro de los amigos, el que clausura el texto. Se trata de un marco homogéneo, cerrado, que contiene en su interior otro, el del segundo narrador. La transformación del marco, la instauración de un marco doble (el subrayado de lo que para algunos constituye la propiedad misma del arte), y el cambio en el sistema de referencias, afectan simultáneamente a dos planos en Fausto: cada cultura se contempla desde la otra y los efectos paródicos de las lecturas mutuas producen transformaciones en el género (separación del contexto político, autonomía literaria), y también en la poesía culta (que argentiniza un corpus europeo y abre una línea que continúa, nítida, en Macedonio y en Borges). Pero además, y sobre todo, el marco produce una autonomía formal: el texto, aislado por el marco de otra cosa que no sea él, se vuelve hacia sí mismo, se autorrefiere y genera división interna, relaciones especulares, paradojas y efectos de autoengendramiento: abre la lectura propia de la serie autonomía-marco-autorreferencialidad-ficción-isomorfismos-dobles. Es decir, su mirada.

Las repeticiones, dobles, simetrías y paralelismos subrayan la duplicación interna, de modo que se encuentra, en cada una de las partes-culturas, temas y formas de la otra:

-Intento de engaño ("cuento") del gringo a Laguna (en pacto comercial, venta de lana). Laguna no se deja engañar: "ya le he maliciao el juego" (v. 120).

-Lamento por pobreza y vejez de Pollo.

-Adorno (joyas) del caballo de Laguna.

- Los dos gauchos mezclan sus almas en el abrazo.
-Pacto del diablo, "cuento" con Fausto (venta de alma). Dice Laguna: " $\_$¿No era un dotor muy projundo? / ¿Cómo se dejó engañar?" (vv. 319-320).

-Lamento de Fausto por la vejez y el amor.

-Regalo de joyas del doctor y el diabio a Margarita.

-Fausto vende su alma al diablo. 
- Robo del cuchillo a Pollo en el teatro. Dice Laguna: "Algún gringo como luz / para la uña ha de haber sido. / - iY no haberlo yo sentido! / En fin, ya le hice la cruz" (vv. 233-236).

-Pollo va al paraíso del teatro Colón (cien escalones).

-Los gauchos conocieron, y Laguna "sirvió" a Fausto Aguilar, coronel "de la otra banda" (vv. 256-264), que también "está en el cielo"' (v. 265).
- Valentín pone el sable ante el diablo: "le presentó / la cruz de la empuñadura" (vv. 555-556).
- Margarita muerta va al paraíso.

-El diablo "sirve" al doctor Fausto: "Aquí estoy a su mandao, / cuente con un servidor', /le dijo el Diablo al dotor, / que estaba medio asonsao"' (vv. 313-316).

Estas reiteraciones y correspondencias entre la situación de enunciación y lo narrado (ópera) establecen una serie de identificaciones: gringo con diablo (los dos hacen cuentos y roban; se ligan además con la cruz del cuchillo-espada); gaucho con doctor (ésta es una identificación negativa: Laguna no se dejó engañar y el doctor sí); gaucho con Fausto (en este caso Pollo: los dos se lamentan de la vejez); gaucho con diablo (los dos sirven a respectivos Faustos); caballo enjoyado con mujer (Margarita); gaucho con mujer (Pollo y Margarita, los "buenos", van al paraíso, donde ya está el militar Fausto). Las identificaciones se ligan con las simetrías, sinonimias, repeticiones, paralelismos ${ }^{13}$, para constituir un discurso cerrado, que se oye decir: con conciencia simbólica. La autorreferencia es el elemento común a los sistemas simbólicos, y aparece en el texto en forma de isomorfismos ("lo mismo" en diferentes niveles: una parte reproduce el todo, un nivel reproduce otro nivel: ser, hacer y decir son lo mismo), y de efectos de autoengendramiento $y$ dobles.

Como se ve, lo que ha sido definido como "específicamente literario" no es sino un avatar del cierre-autonomización de lo escrito y de un lugar de lectura. Y la autorreferencia produce, ade-

${ }^{13}$ Se puede añadir la simetría especular de la décima: abbaa/ccddc, y el uso de la homonimia, que se liga con la figura del doble. Además toda una estética de los matices (rosado, colorado, mar, Laguna, etc.) y el juego de los significantes y su relación casi siempre generativa: Mar-garita, mar, mañana (III, v, 433), y la mujer-flor (Margarita). Algunos de estos aspectos están excelentemente analizados en el "Estudio preliminar" de Noemí Susana García y Jorge Panesi a la edición de Fausto, Colihue, Buenos Aires, 1981. 
más, las típicas paradojas que hacen indecidible la relación del sistema simbólico con la verdad y con el sentido, y suscitan dispersión. Como se sabe, para resolver las paradojas se hace necesario pasar a otro nivel, verbal o narrativo; pero si el texto juega precisamente en la oscilación entre dos (narradores, situaciones, espacios, Faustos, culturas, paraísos) o entre cuatro -su duplicación - y cierra el juego, la indecibilidad se instala y produce ficción con dos de sus rasgos básicos: más allá de lo verdaderofalso e identificación entre constatativo-realizativo. En un círculo característico de estos sistemas, los dobles, isomorfismos y autoengendramientos representan a su vez el carácter ficticio e indecidible del texto. Dicho de otra manera: las paradojas y reenvíos excluyen toda autoridad, todo nivel o instancia superior que pueda resolverlas en relación con el sentido y la verdad. En Frusto las direcciones referenciales funcionan al mismo tiempo (se superponen) y en doble nivel. En primer lugar la referencia a la ópera, que es ya una representación. En segundo lugar las referencias cruzadas de cada cultura a la otra, con uso de parodia y con ironía, es decir, escisión (también indecidible) entre enunciado y enunciación, doble palabra y oscilación alrededor de la creencia. En tercer lugar autorreferencia y cierre, que produce autoengendramientos, dobles, paradojas y recursividad; esta autorreferencia también constituye un sistema jerárquico (no es chata, como la idea de anverso/reverso), pero el otro nivel no resuelve las paradojas del primero, sino que las reitera o invierte: las cadenas jerárquicas pueden proliferar en series que, por lo general, se cierran en el punto de partida. En Fausto el cuento funciona como elemento de escansión y de organización del texto:

"con el cuento de la guerra" (v. 121)

"el cuento que le he ofertao" (v. 284)

"¿Sabe que se me hace cuento?" (v. 362)

"Y áhi tiene el cuento contao" (v. 1258).

El cuento aparece en las dos culturas, en el enunciado y la enunciación, en los narradores y en lo narrado:

-Primer narrador y su cuento: "se creería",

- cuento de Laguna a Pollo (sobre el caballo, no cree);

- cuento del gringo a Laguna (que éste cuenta a Pollo: se trata del pacto económico de lana; Laguna no cree).

-Segundo narrador (Pollo a Laguna: cree la ópera como ocurrida):

- cuento del diablo a Fausto (pacto de alma, cree);

- cuento de Fausto a Margarita (engaño, seducción, cree). 
Un narrador cuenta un cuento (género gauchesco) dentro del cual otro narrador (Pollo) cuenta otro cuento (ópera), que contiene diversos cuentos (engaños). Solamente se creen los cuentos ligados con supersticiones y los cuentos del arte: son los verdaderos cuentos. El texto explora la diferencia entre los "cuentos" (mentiras, exageraciones, estafas, engaños) y las creencias en las dos culturas, contados unos y otras literal e irónicamente, y encajados unos en otras: el marco del primer narrador y su cuento irónico del género incluye los cuentos de y a Laguna (sobre el caballo y sobre el dinero del gringo), que los gauchos, Pollo y Laguna respectivamente, no creen; el marco del segundo narrador, el Pollo y su cuento irónico de la ópera desde el género, incluye los cuentos del diablo a Fausto y de éste a Margarita, que todos creen.

Se cumple así la mutación del género por el pasaje del pacto al cuento.

Los efectos de la parodia y de la despolitización del género en Fausto definen y sitúan nuestra lectura.

El género gauchesco anterior representó, en la construcción de la alianza militar, el antagonismo de las masas rurales contra los enemigos de la patria y la libertad (y su subordinación a la figura del que manda). Integró la cultura y el tono oral de los gauchos con la otra, se ligó con sus elementos más visibles de agresión (o lo que creyó agresión popular) y los dirigió contra el enemigo: usó su lengua como arma. Representó también, en la construcción de la alianza política, a la figura del gaucho (a su registro) como crítico del enemigo, en la forma de lamento por la injusticia. El centro de muchos poemas-diálogos gauchescos lo ocupa el código jurídico, la ley liberal (y su recitante, el que sabe) que se debía inculcar a los gauchos: usó su lengua como ley. Politización e integración a la ley se identifican: unificación política y jurídica en el mapa del Estado.

Pero la despolitización y la ficcionalización de las representaciones de las alianzas del género, que lleva a cabo Fausto (cerrando la historia de los diálogos de visita a la ciudad), acarrea una serie de consecuencias. La inmediata es la aparición de una zona de la cultura oral sin función política (sin uso posible): las creencias, los cuentos y las miradas y, correlativamente, la aparición de otra función de los escritores del género: no ya la construcción de las alianzas y el recitado de la ley, sino la búsqueda de otro hacer creer y de los verdaderos cuentos. Como se ve, las funciones están en función recíproca.

Despolitizar y excluir el código jurídico son uno en Fausto. Y si el código jurídico deja de tener vigencia: 
a. El código artístico, el de las representaciones creíbles, ocupa el conjunto del texto e instaura un espacio sin aliados ni enemigos; sin coacción ni represalias. Un código, con la ficción y la parodia, donde se puedé matar sin culpas, y un vaivén del sentido que excluye toda autoridad o tribunal que pueda fijarlo.

b. El texto se expande en una multiplicidad de códigos, normas y pactos: pactos y códigos narrativos, tratos de compraventa, normas de juego, pactos de servicio. Fausto cuenta el juego de la pluralidad de leyes cuando cae la Ley.

c. El primer plano del texto (de su escena) lo ocupan el abogado Fausto y su pacto perverso, legal e ilegal a la vez.

d. Y puede aparecer, por primera vez en el género gauchesco, un código popular de justicia consuetudinaria, opuesto y enfrentado a la ley letrada. Surge la justicia por cuenta propia, la venganza, y la protección y solidaridad de los iguales, es decir otra alianza y otro consenso: "Cuando a usté un hombre lo ofiende, / ya, sin mirar para atrás, / pela el flamenco y ¡sas! ¡tras! / dos puñaladas le priende. / Y cuando la autoridá / la partida le ha soltao, / usté en su overo rosao / bebiendo los vientos va. / Naides de usté se despega, / porque se haiga desgraciao, / y es muy bien agasajao / en cualquier rancho a que llega" (vv. 921-932).

Dicho de otro modo: los elementos de la cultura popular no integrados en alianzas, sin uso para la cultura letrada, establecen otra mirada, otra legalidad y otro consenso que particularizan la legalidad dominante. $Y$ entonces, de un modo ambiguo y doble, como en la parodia, se enfrentan las culturas en la forma de dos particularismos o especificidades y no ya como centro y periferia. Dos espacios paralelos y relativos que levantan los dos pilares con que se sostiene, simétrico, el texto.

Y si se lee a Fausto desde el género anterior (si se rompe la autonomía y la autorreferencia y la indecisión del sentido: si se quiere terminar con el vaivén) y desde el relato de Pollo y desde otra alianza, utópica, puede imaginarse otro tipo de relación entre política y literatura, más allá de la política del género. Puede verse la lectura del gaucho, su mirada de la ópera, como un gesto de resistencia: un uso del código del otro (aceptado pero no reconocido) y a la vez del propio. Pero sin alianza, porque la resistencia es la contracara de la alianza.

El corte que Fausto produce en la tradición gauchesca es el ataque a los dos sectores que constituyeron la alianza básica de las representaciones del género: el doctor (el que sabe y el dueño de la ley) es engañado en un pacto por alguien más astuto, el diablo; el diablo mata, además, al militar hermano de Margarita. 
En los diálogos de Araucho y de Ascasubi el diablo se ligaba con la ciudad (lugar del desorden y del engaño), y en el de Ascasubi, además, los doctores podían "chuparle el corazón al diablo, / si se le antoja meterse a pleitiador". En Del Campo, según el procedimiento paródico de inversión generalizada, es el diablo quien embauca al doctor y aparece como el astuto supremo.

Como se sabe, la autonomía y la autorreferencia producen duplicaciones, identificaciones y equivalencias. Hay dos Faustos: el doctor de la ópera y el coronel de la otra banda: “- ¿Dotor, dice? Coronel / de la otra banda, amigaso; / lo conozco a ese criollaso / porque he servido con él", dice Laguna (vv. 257-260). Y Pollo: "Déjeló al que está en el cielo, / que es otro Fausto el que digo, / pues bien puede haber, amigo, / dos burros del mesmo pelo" (vv. 265-268). Esta equivalencia (identificación y oposición) se refuerza porque los dos Faustos tienen quien los sirva (militare no sólo quiere decir combatir sino también servir): los gauchos soldados por una parte, y el diablo por la otra: "Mi dotor, no se me asuste, / que yo lo vengo a servir; / pida lo que ha de pedir / y ordénemé lo que guste" (vv. 317-320). Los gauchos se ligan e identifican con el diablo por el paralelismo de los dos pactos de servidumbre. Y el relato de la ópera muestra que el diablo (¿los gauchos?) socava el poder del que sabe y del que manda. En la duplicación generalizada, aparece otro militar (dos Faustos y dos militares), el hermano de Margarita, "capitán muy guapetón / que iba a dir al Paraguay" (vv. 491-492) que no muere en el campo de batalla sino que es matado por el diablo en su propio terreno, la lucha. El diablo vence así a cada uno en su campo: al doctor, transformado en abogado en el texto, en un trato o pacto legal: "Si se topó ese abogao / con la horma de su zapato?" (vv. 395-396).

Hay, también, dos diablos. El del relato de Laguna sobre el juego, que ganó: "Primero le gané el freno / con riendas y cabezadas, / y en otras cuantas jugadas / perdió el hombre hasta lo ajeno. / ¿Y sabe lo que decía / cuando se vía en la mala? / El que me ha pelao la chala / debe tener brujería. / A la cuenta se crería / que el Diablo y yo..." (vv. 145-155). Y esto motiva la intervención de Pollo: él vio al diablo en persona. El que juega cree que el diablo ayuda a Laguna, que tiene una alianza con él; el diablo puede ser, entonces, un aliado, una fuerza benéfica. Pero Pollo introduce, inmediatamente, su sentido negativo ${ }^{14}$, el de enemigo. Se trata de un per-

${ }^{14}$ Cf. JACQUes Le GoFf, "Cultura clerical y tradiciones folclóricas en la civilización merovingia", en Niveles de cultura y grupos sociales, Siglo XXI, México, 1977. Opone el carácter ambiguo y equívoco de la cultura folclórica 
sonaje ambiguo, de doble faz, aliado y enemigo, que tiene con el doctor la misma relación que puede tener cualquiera que pacte, en un pacto desigual, de servidumbre: puede ayudar y atacar. $Y$ lo que Pollo contempla en la ciudad, en su escenario, y cuenta con gozo a Laguna en el bajo, es cómo el diablo, enviado por la cultura europea, deja en ridículo, como tontos que creen los cuentos, a los doctores de la ciudad. El diablo es al doctor lo que éste a los gauchos.

El relato del gaucho cuenta al mismo tiempo que el doctor, aprovechándose de la ausencia del militar por la guerra (el doctor dueño de la ciudad y de la ley, sin oponentes), se alía con el diablo para engañar a la hermana del militar. Mientras el que sabe y el que manda, representados por la voz de los escritores del género, visitaban el campo para proponer alianzas a los gauchos, el gaucho en la ciudad contempla ahora el espectáculo de su lucha: lucha, en realidad, entre ellos, cada uno con sus servidores. Y en esa disputa el escritor, que piensa ahora la construcción de representaciones creíbles (cómo contar cuentos) y la argentinización de la cultura europea, se distancia como el gaucho, se sitúa en el vaivén, en el entre: en el trazado de los cruces y superposiciones de las dos culturas y las dos lenguas literarias.

La ambivalencia, la resistencia, invaden el texto y el doble juego no tiene fin (militares, Faustos, diablos, gauchos, buenosmalos, aliados-enemigos). Porque el sentido no responde solamente a las palabras sino también a las acciones: juicio burlesco al género en un poema que ha sido leído como una burla del gaucho. El relato de la ópera pone en escena una venganza simbólica, y el simbolismo popular puede funcionar como agresión, venganza y muerte si permanece velado $y$ ambivalente ${ }^{15}$, tan ambiguo como

(creencias en fuerzas buenas y malas a la vez, empleo de un "instrumental cultural de doble filo") al racionalismo de la otra cultura, que separa polarmente bien y mal, verdadero y falso.

${ }^{15} \mathrm{Cf}$. especialmente, sobre los elementos de resistencia de la cultura popular, MICCHEL DE CERTEAU, L'invention du quotidien, t. 1: Arts de faire, Union Générale d'Éditions, Paris, 1980, caps. 2 y 3. Y, sobre todo, ROBERT DARNTON, The Great Cat Massacre, and Other Episodes in French Cultural History, Random House, New York, 1985. Dice Darnton, cuando analiza el episodio de la "Masacre de los gatos", que el débil, pero vivo, transforma al opresor en bobo y desencadena risa. Las "trampas" permiten al pobre lograr una ventaja marginal, jugando con la vanidad y estupidez de sus superiores. Y, sobre todo, que el simbolismo popular disfraza el insulto para que no tenga consecuencias; juega con acciones y ambigüedades que ocultan su sentido. Las protestas populares en Francia, hasta el surgimiento de la proletarización a fines del siglo XIX, tenían un nivel sobre todo simbólico. 
para atacar a doctores y a militares y a la vez exaltar y matar a estos últimos (los militares "buenos" también están muertos, los que no mueren son los gauchos y el diablo). Ahora el vivo es el gaucho, que (¿aliado con el diablo?) se ríe del género, el doctor del cuento. El gaucho en la ciudad ha encontrado otra vez la letra, en la forma de una representación, cuyo relato (duplicación) deshace el género gauchesco y al mismo tiempo lo integra definitivamente en la literatura.

Un texto sin alianzas, donde los gauchos pueden decir sin represalias. Esto ocurre también en "Gobierno gaucho", el otro poema de Del Campo, donde el gaucho borracho, transformado en otro, toma el poder y manda y legisla con la única alianza del alcohol: contra la leva, contra los acumuladores de tierras, contra el alcalde, el comandante, el juez, el pulpero, la papeleta.

JOSEFINA LUDMER

Universidad de Buenos Aires 